\title{
Imagem é aquilo que contrai e dilata
}

\section{Image is what contracts and dilates}

\section{Lucas Martins Dalbem}

Mestrando em Teatro pelo programa de Pós-Graduação em Teatro pela Universidade do Estado de Santa Catarina (UDESC). Professor, diretor e ator. Possui trabalho de treinamento de atores e atrizes através da técnica em Mimo Corporal. Membro do coletivo de teatro Dizputa Sitiada. Estuda (des)hierarquização das funções teatrais, relações de poder e encenação teatral. Atualmente está interessado em processos e pessoas que estudam e exercitam o aprender a aprender. - lukasdalbem@gmail.com https://orcid.org/0000-0003-0993-5040

(Sob supervisão de)

\section{Fátima Costa de Lima}

Professora titular do Departamento de Artes Cênicas do CEART e do PPG em Teatro da UDESC. Doutora em História Cultural (PPG em História do CFH/UFSC). Atuação artística: atriz, carnavalesca, cenógrafa, figurinista e diretora teatral. Pesquisa teatro e carnaval. Referencial: teoria crítica. Temas: espaço, imagem e alegoria em teatro político, teatro negro, movimentos sociais e escolas de samba. costadelimafatima@gmail.com - https://orcid.org/0000-0001-8498-5000

\section{Resumo}

Este ensaio é um exercício reflexivo sobre a desierarquização das funções teatrais, o olhar e a imagem. $O$ texto tem como disparador o relato de um acidente que ocorreu com o próprio autor, organizado em pequenas teses numa linha temporal cronológica. A partir dele se destrincham discussões críticas acerca da metodologia do olhar racional na história da arte, na organização das funções teatrais e na construção e produção de imagens. Este ensaio é sobre colocar duas coisas que não podem estar juntas no mesmo espaço-tempo, contrair e dilatar.

Palavras-chave: Teatros. Imagem corporal nas artes cênicas. Performance (Arte).

\section{Abstract}

This essay is a reflective exercise on the de-hierarchization of theatrical functions, the look and the image. The text triggers the report of an accident that occurred with the author himself organized in small theses in a chronological timeline, and from it brings critical discussions about the methodology of the rational look in art history, in the organization of theatrical functions and in the construction and production of images. This essay is about putting two things that cannot be together in the same space-time, contracting and expanding.

Keywords: Theaters. Body image in the performing arts.Performance (Arte)

DOI: http://dx.doi.org/10.5965/1808312915252020e0026 
Em uma das andanças mentais, por meio de pensamentos pendurados e ideias molhadas, decidi buscar na trama de minha pesquisa as linhas que poderiam guiar a costura desta escrita. Tendo em vista a proposição de realizar um trabalho teóricoprático, neste ensaio escolhi seguir operação semelhante. Para isso, narrarei um acidente que ocorreu comigo no dia 22 de junho de 2019, um mês antes de eu começar a escrever o presente texto. $O$ acidente em questão serviu como inspiração para relacionar conceitos à linha de costura desta trama tecida aqui.

Decidi contar o ocorrido através de pequenas teses em talhe episódico, separadas numa esteira cronológica de 15 minutos. A narrativa tem início às $16 \mathrm{~h} 50 \mathrm{~min}$ e o seu final às $17 \mathrm{~h} 05 \mathrm{~min}$. Esta é uma tentativa de apresentar alguns dos atravessamentos produzidos durante a pequena e curta saga da magrela comigo. Ao fragmento sobre o qual discorrerei a seguir, chamarei de: "IMAGEM É AQUILO QUE CONTRAI E DILATA". Logo após a narrativa, se desenvolverá, em moldes mais restritos de escrita, o pensamento ao qual me proponho enquanto pesquisador em teatro com os materiais apresentados. Não evidenciei (ainda) minimamente do que se trata minha pesquisa. Portanto, peço paciência. Espero - através deste fragmentário narrativo - evidenciar e confundir as minhas ideias (assim como as suas). E a partir disso, pô-las em jogo. 


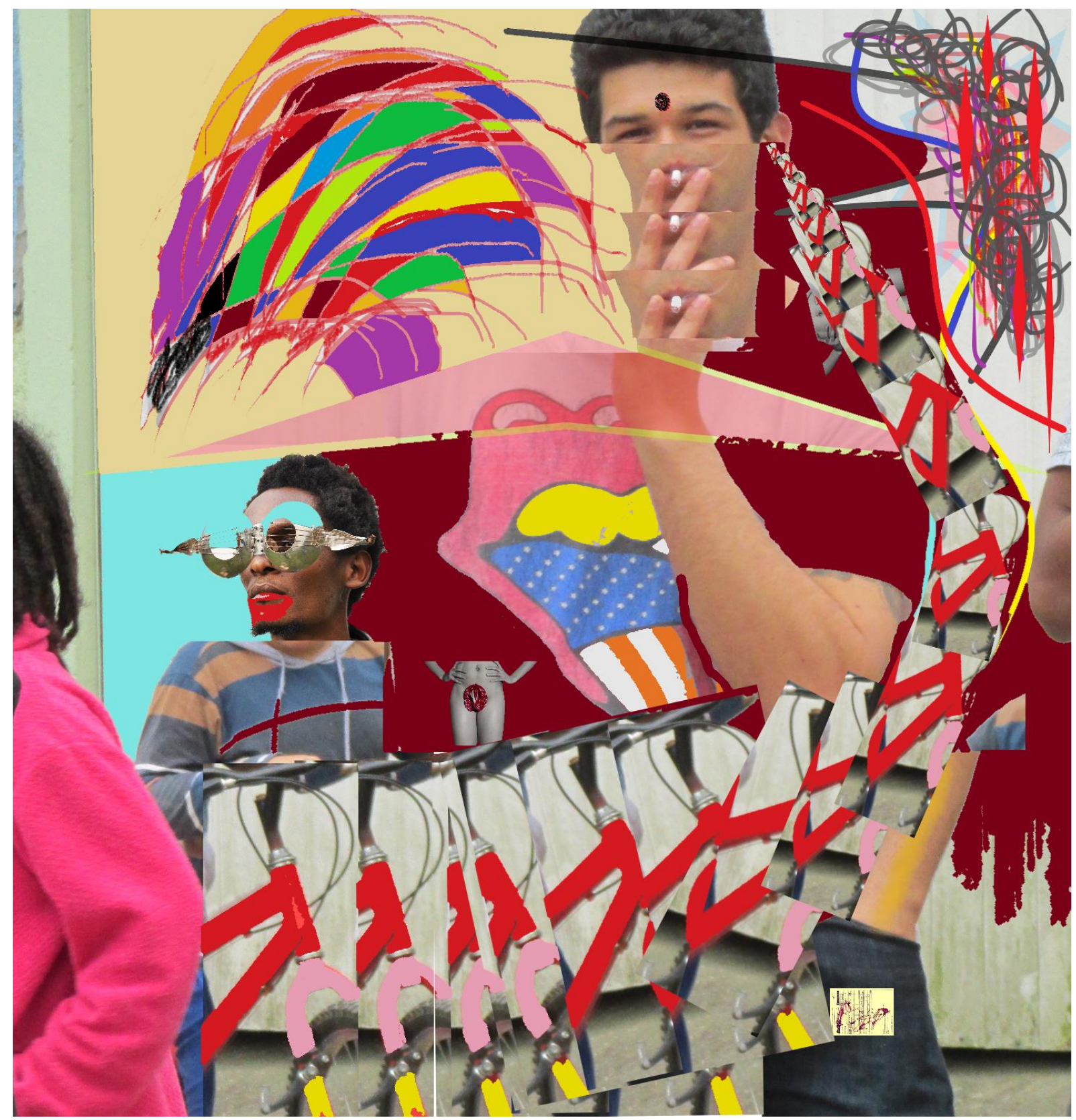

Bikezada holística na serrinha, $2018^{1}$

\begin{abstract}
${ }^{1}$ Montagem e fotografia de minha autoria, realizada no Paint 3D sobre uma fotografia de moradoras e moradores do Morro da Serrinha vendo a apresentação da montagem teatral $A$ Invasão, com direção e adaptação de Stephan Baumgärtel da peça teatral homônima do dramaturgo brasileiro Dias Gomes. A peça foi resultado da disciplina de Montagem Teatral 2016/1 e 2 do curso de Licenciatura em Teatro da UDESC, e nela fui monitor responsável pela preparação corporal do elenco, como também em realizar registros dos momentos de montagem das apresentações. O espetáculo aconteceu no espaço de um estacionamento de chão batido em frente à moradia de algumas pessoas da comunidade. Morro da Serrinha, Florianópolis/SC.
\end{abstract}


Sábado, dia 22 de junho de 2019. Florianópolis - SC.

16h50min

Tarde ensolarada na cidade. Um daqueles dias preciosos. A ânsia de fazer algo com o corpo. Inquietude. O corpo não encontra vazão dentro do apartamento, é necessário sair, laçar os últimos raios de luz como se fosse escurecer para sempre. A única forma de fazê-lo: arremessar o corpo para dentro da imagem (que estava fora).

\section{6h53min}

Pus minha regata listrada em tons intercalados de cinza e branco, uma sunga preta, boné verde musgo e tênis esportivo colorido em tons escuros. O quadro é guiado com trilha sonora de Madonna no final dos anos 90: época de seu retorno estrondoso para a indústria fonográfica escrevendo canções em sânscrito e dizendo que havia mudado a cabeça: Now I find, I've changed my mind, this is my religion ${ }^{2}$. Os ventos estavam favoráveis.

\section{6h55min}

Observando a justaposição de peças ambulantes, a regata estilo marinheiro/remador e o boné verde musgo desbotado, me brota a imagem de um dos personagens do romancista francês Jean Genet (1910 - 1986) em Querelle de brest, principalmente a versão cinematográfica de $1982^{3}$, interpretada por Brad Davis. Atracado no porto, disposto e sedento a desafiar o espaço-tempo e dobrar 10 esquinas no mesmo instante.

\footnotetext{
${ }^{2}$ Disco Ray of Light, lançado por Madonna em 1998. A citação da letra vem da música Drowned World/Substitute for Love, que faz a introdução do disco.

${ }^{3}$ Querelle é um filme de 1982, de produção franco-alemã, baseado no romance de Jean Genet Querelle de brest, dirigido pelo cineasta alemão Rainer Werner Fassbinder.
} 
16h57min

Decidi sair de bicicleta. Engatei nos pedais e segui em direção à Ponta do Coral. Num raio deslizante, logo depois de desviar da casa da Agronômica e sair da rua Delminda Silveira em direção à ponta ${ }^{4}$, me deparo com o quadro clássico e cotidiano das famílias residentes da área: o pôr do sol à beira-mar. Uma sina (ou praga) impressionista. Um escorpião perfumado cadenciado em frames de céu. Selvagem e vigilante.

\section{7 h00min}

Mais do que pela IMAGEM, fui encantado pelo olho. Num processo de autofeitiço, fui que nem mosquito em direção à luz. Em busca de quê? O que move? O que atrai? IMAGEM de contemplação. À procura de um símbolo de virtude, um resgate em alto-mar, como se apenas restasse essa última alternativa. Independente do que se procura, a IMAGEM imprime algo, produz - inclusive, mais do que ela comporta, mais do que ela representa ou do que se sente e vive sob a IMAGEM (no caso, o pôr do sol). É um lembrete ilegível balbuciado em câmera lenta.

\section{$17 \mathrm{~h} 03 \mathrm{~min}$}

Curiosamente, todo o caminho feito era extremamente ordinário: o granulado do asfalto, os passantes pequeno-burgueses, as sinaleiras piscando em amarelo, o tempo largo de atravessar, a inclinação da bicicleta ao realizar uma curva... Costumeiro como o andar para frente. Mas, como todo costume que tenho, tendo a esconder um grão de estranhamento dentro do olho, que cresce a cada coçada. Escavar algo intimamente novo. Enquanto isso, a IMAGEM do pôr do sol continua intacta, um quadro esculpido, pelo olho, de encaixe (quase) perfeito no imaginário de gerações.

\footnotetext{
${ }^{4} \mathrm{O}$ trajeto ao qual me refiro aqui tem como ponto de partida o final da rua Delminda da Silveira, do lado esquerdo, tomando como referência a Casa da Agronômica, dando de costas à beira-mar no bairro Agronômica, Florianópolis (SC). Desse ponto eu desço a rua Delminda Silveira e realizo uma curva em direção à ponta do Coral, onde se encontra atualmente a APPC: Associação de Pescadores da Ponta do Coral, que resiste em disputas de diversas ordens com o Poder Público e empreiteiras do setor privado.
} 


\section{7h05min}

Num movimento de despressurização da cabine do voo automobilístico IMPACTO a SECO - IRRUPÇÃO, atravessa um carro no meio da bicicleta. Os materiais mudam. Tornam-se outros: o saco de amendoins dentro da bolsa vira chuva e o corpo vira carcaça. A música de Madonna escapa, e torna-se um eco distante. A bicicleta é arremessada para frente como um projétil mortal. Finalizo no chão. O corpo e o que sobrou da pancada: Uma IMAGEM. Uma outra, talvez a mesma, porém rasgada. Uma IMAGEM rompida.

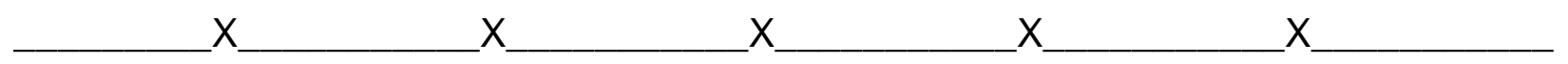

"A relação do olho com o mundo é, em realidade, uma relação da alma com o mundo do olho". Com essa frase de Erwin Panofsky citada por Didi-Huberman (2013, p. 187) no livro Diante da Imagem, dou início ao destrinchamento de um dos corpos deste ensaio: a imagem.

Pela ótica da história da arte, o teórico Didi-Huberman põe em jogo as concepções que abarcam a problemática da imagem e do conhecimento sobre esse tema. Contudo, o autor não aborda o tema imagem de modo generalista; ele apresenta uma operação. No capítulo "Imagem como rasgadura e a morte do deus encarnado", Didi-Huberman (2013) comenta sobre uma renúncia. Uma renúncia que precisa ser feita na história da arte: pensar (logo, ver) a imagem não apenas como representação, ou como forma de um desenho em sua natureza figurativa, mas sim numa forma expandida. Renunciar ao esquematismo da história da arte. O autor propõe como alternativa a rasgadura da imagem. Mas, que rasgadura? Rasgadura em relação a quê? Uma renúncia ao esquematismo da história da arte, tendo como via de ação a rasgadura do que se concebe enquanto imagem. Evidencia-se aí uma metodologia. Um ângulo de ataque que vise a ruptura da ideia que se concebe a partir da imagem.

Logo após a batida do carro contra a bicicleta, me mantive no chão por alguns momentos. Desnorteado e incapaz de me levantar imediatamente, movimentei as minhas pernas pra verificar se não havia fraturado nenhum osso. Por sorte vazada, nada de grave aconteceu com o corpo. 
Uma grande porção de pessoas observaram espantadas a cena do atropelamento. $\mathrm{O}$ motorista desceu do carro e ofereceu ligar para a emergência. Eu pedi para que não ligasse: preferi, naquela situação, realizar um acordo verbal na tentativa de impedir o prejuízo da parte dele do conserto e não ter mediações de quaisquer instituições (já que eu não havia me machucado gravemente e também por conta do homem ter alegado falta de dinheiro, pois tinha acabado de quitar dívidas) ${ }^{5}$.

Trocamos números de celular e ele colocou minha bicicleta destruída em cima de seu bagageiro, oferecendo-me uma carona para casa. No trajeto de volta, apresentouse uma oportunidade para entender minimamente qual fora a força responsável pelo atravessamento abrupto. Ao som de uma estação de rádio da Igreja Universal, a força se identificou como Raí: homem negro, pai de 3 filhos, instalador de vidros temperados em edifícios possivelmente gratinados em especulação imobiliária, alguns deles localizados na avenida Beira-mar - onde muito pouco provável seria sua residência ou de sua família (mesmo se o quisesse por vias éticas).

Contei de minha condição de estudante de Teatro na universidade e professor da rede pública de ensino, buscando alguma espécie de cumplicidade. Mas era nítido o lugar distinto, de formação e de vida, no qual me encontrava em relação ao dele. Sem dúvidas, o encontro-acidente denunciava o nosso abismo de classe e privilégios de diversas ordens. Por outro lado, nessa disparidade escancarada entre a força de atropelamento chamada Raí e a justaposição ambulante na qual eu me encontrava, existia um estranho elo que nos aproximava: dentro daquele automóvel, havia dois montadores: um montador de vidros temperados em prédios, e eu também um montador, porém de outra natureza.

Talvez não um montador de bicicletas quebradas ou de prédios comerciais, mas um montador de pensamentos; ou, no teatro, de cenas poéticas interligadas por linhas espaço-temporais diversas. Como pesquisador e diretor de teatro encontrei dificuldade de dizer que éramos de fato parecidos: assemelhar o trabalho de montagem de peças de construção com o trabalho de um diretor de teatro - ou até mesmo de um

\footnotetext{
${ }^{5}$ Após o ocorrido, ao regressar à minha casa, realizei uma breve procura na Internet sobre como agir em situações de acidentes trânsito envolvendo bicicletas. No caso específico em que há atropelamento por automóvel com alguém em maior situação de vulnerabilidade (pedestre, ciclista e motocicleta), por lei a pessoa que se encontra no automóvel deve arcar com todos os custos de reparação dos danos causados.
} 
pesquisador - soa como algo assimétrico? Como explicar um olhar poético sobre a vida? Qual trabalho discursivo é possível ser realizado, capaz de produzir linhas de pensamento que aproximem diferentes experiências do ver? Ao enxergar, como produzir discursivamente o que se vê para que se modifique o olhar e, numa espécie de movimento de contração e relaxamento, se exercite o músculo dialético contínuo de transformação e reinvenção? Contrair e dilatar, assim como o músculo da panturrilha ao pedalar numa ladeira. Expandir e arejar, fazendo saltar suavemente sobre a superfície da pele veias latejantes da estrutura interior. Desvelar, mesmo que por instantes, do que se é feito.

A partir desses questionamentos, faço um breve retorno ao início do pensamento traçado por Didi-Huberman sobre a imagem. Para que se imagine uma outra forma de ver a imagem, o autor sugere "rachar ao meio a noção simples de imagem [...] rachar ao meio a noção simples de lógica" (Didi-Huberman, 2013, p.187). Mas rachar como? Segundo Didi-Hubermann (2013, p. 187):

rachar ao meio a noção de imagem seria, em primeiro lugar, voltar a uma inflexão da palavra que não implique nem a imagística, nem a reprodução, nem a iconografia, nem mesmo o aspecto "figurativo". Seria voltar a um questionamento da imagem que não pressuporia ainda a "figura-figurada" [...] o processo, o caminho, a questão em ato, feita cores, feita volumes [...] abrir a caixa, abrir os olhos à dimensão de um olhar expectante [...] tocar com o dedo o valor virtual daquilo que tentamos apreender sob o termo visual.

Um dos exemplos que o autor utiliza para evidenciar a abordagem não apenas racional e figurativa da imagem, mas também expandida e plural, é a obra $A$ Interpretação dos Sonhos do psicanalista austríaco Sigmund Freud (1856-1939). A partir dela, o autor endossa o seu pensamento de imagem através de uma valorização do negativo e da "força do negativo na imagem" (Didi-Huberman, 2013, p. 190) que se dá através do sonho. "Trata-se apenas de dialetizar: pensar a tese com a antítese, a arquitetura com as suas falhas, a regra com a sua transgressão, o discurso com seu lapso, a função com a sua disfunção [...] o tecido com a sua rasgadura" (DidiHuberman, 2013, p. 190). 
Resgatando a ideia de ser um montador no sentido da arte teatral, aproveito para introduzir o tema de minha pesquisa: a desierarquização das funções teatrais ${ }^{6}$. Como pesquisador, pretendo encontrar estratégias de subversão no regime de organização hierárquica das pessoas envolvidas num processo de criação. Não tenho como intenção apenas diluir o poder que se produz nessas inter-relações, mas propor modelos de rotatividade e autonomia, com o desejo de diminuir a tendência de cristalização e personificação dos agentes criativos em determinada(s) função(ões). Para endossar o pensamento de desierarquização das funções, penso que é necessário acessar o imaginário. No que percebo, ao iniciar qualquer tipo de processo de criação, é preciso estabelecer um ponto de partida em como trabalhar e com quem será feito o trabalho, especialmente num processo desenvolvido de forma colaborativa.

O termo "ponto de partida" não significa que se está começando algo totalmente novo, ou que a partir desse determinado ponto começará uma "nova história" que anule o que veio anteriormente. Muito pelo contrário, estabelecer um ponto de partida é construir um vértice coletivo onde todas as pessoas envolvidas possam, a partir desse ponto, estabelecer um diálogo, um denominador comum, um ponto onde se encontram as histórias, os pensares, as concepções e os afetos que compõem a teia do trabalho de criação.

As estruturas de poder que constroem e regem a hierarquia num processo criativo teatral pouco ou nada parecem diferir das estruturas de poder vigentes na sociedade. Não são exclusivas do território das artes as relações entre diretor e ator, mestre e pupilo, ou professor e aluno. Trata-se de relações de autoridade historicamente construídas, que permeiam diversos espaços de aprendizado e produção na sociedade de modo geral. E é justamente apoiada nessa estrutura que se encontra parte do fazer teatral hoje, onde tensiono ao questionar a formatação. Para isto, pretendo localizar e mover os limites e brechas que impedem que outras formas de relação tomem espaço.

\footnotetext{
${ }^{6}$ Com o termo "funções", pontuo as atividades que tradicionalmente permeiam o processo de construção de alguma peça teatral: ator, atriz, diretor(a), iluminador(a), cenógrafa(o), dramaturga(o), dramaturg, preparador(a) corporal e sonoplasta, entre outros(as).
} 
A concepção representacional e figurativa de imagem criticada por DidiHuberman, a partir de uma abordagem não exclusivamente racional, propõe uma operação da imagem - uma metodologia - como dito anteriormente. A imagem como rasgadura possibilita a apresentação (ao invés de representação) da copresença de qualidades dicotômicas em detrimento da exclusão por anulação do diferente, comumente estabelecida através do termo "ou". Assim, é revelado um dos efeitos limitantes da natureza da representação. A ação de comparar duas ou mais elementos vem da ordem da representação. Tomo essa operação como guia de não somente sobre a leitura e produção de imagem, mas também para um redimensionamento dos meios de produção, inferindo diretamente na formatação de um processo de montagem.

Nessa linha de pensamento, o filósofo alemão Walter Benjamin (2017) em seu livro Ensaios sobre Brecht traz em análise do drama familiar no teatro épico, uma proposta feita por Brecht dentro do teatro épico: uma "mudança de função", um brincar de trocar de lugar. Walter Benjamin comenta: "Agora chegou o momento de inverter as posições, de perguntar: a mãe está no comando, mas e o filho? Pois é o filho quem lê os livros e se prepara para a chefia. São os quatro - mãe e filho, teoria e prática - que se reagrupam; brincam de trocar de lugar" (Benjamin, 2017, p. 41). Nesse jogo de troca de lugar emerge a percepção de que os lugares que se assumem não são eternos ou imutáveis (a máxima: "as coisas sempre foram assim") e sim passíveis de serem modificados e reestruturados. No caso do drama familiar, a mãe como a "prática encarnada do comunismo" (Benjamin, 2017, p. 41); e o filho, como a fonte teórica necessária para a luta de classes. Na proposta de troca, os lugares se apresentam como funções a serem ocupadas (e desocupadas) e o brincar de trocar como mecanismo.

$\mathrm{Na}$ imagem esculpida em minha curta viagem de bicicleta, me deparei acidentalmente com a força Raí, em formato de movimento rasteiro por de trás da cabeça, um sequestro da ilusória paz do entendimento racionalizado. Com ele fui arremessado para outro lugar, onde as coisas assumiram outras formas e funções. $O$ corpo aparentemente invencível e revestido de referências reduziu-se a matéria de carne \& ossos. Nessa matéria, a representação não encontrou mais espaço ou, 
simplesmente, não mais coube dentro do acontecimento. A força do atropelamento proporcionou um rasgo na imagem, para surgir outra sobre ela mesma, uma justaposição estilhaçada. No momento, me interessa produzir este tipo de operação.

Assim como Didi-Huberman utiliza o conceito de "imagem como rasgadura" como proposição, me pergunto se seria possível propor atropelamentos no olhar (e no fazer), com o intuito de tornar as coisas outras sobre elas mesmas. E radicalmente, em movimento rasteiro, pôr o que se põe em fortaleza na fragilidade e a fragilidade em fortaleza; o retraído no expansivo e o retraído em expansão; a teoria na prática e a prática como teoria. E nisto, produzir uma imagem: uma imagem rasgada pendurada num estandarte, uma imagem de paisagens bonitas estirada no asfalto, uma imagem refletida no vidro de um prédio em ruínas à beira-mar, uma imagem costurada pelos dentes da boca e manchada pelos dedos das mãos, uma imagem antes de ser nomeada como imagem. Uma imagem.

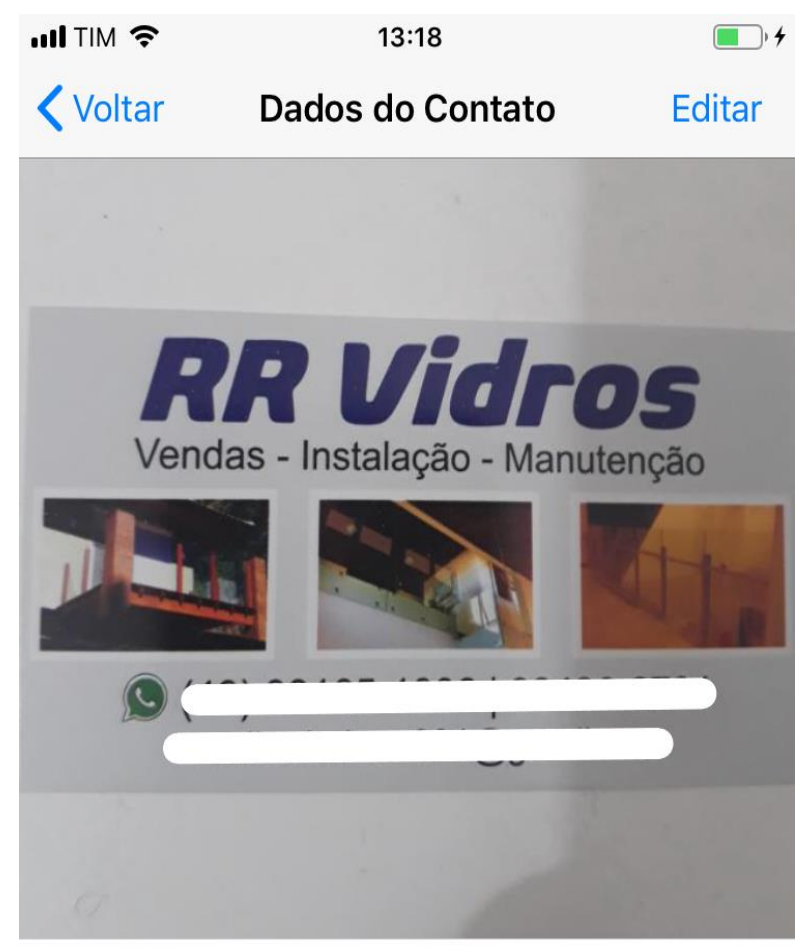

Rai Bike Atropelo

Não importa qual o caminho vc escolha e sim a 
Printscreen feito pelo meu celular com os dados de Raí que registrei no dia do acidente - os quais suprimi, pois não há necessidade em expor assim como a sua foto de perfil e status no aplicativo do WhatsApp.

No final da negociação verbal (na qual houve resistência por parte de Raí em pagar mais de $70 \%$ do prejuízo feito com a bicicleta), decidimos cada um pagar $50 \%$ do orçamento do conserto, dando o total de 400 reais. 


\section{REFERÊNCIAS}

BENJAMIN, W. Ensaios sobre Brecht. São Paulo: Boitempo, 2017.

DIDI-HUBERMAN, G. Diante da imagem: questão colocada aos fins de uma história da arte. São Paulo : Editora 34, 2013.

FREUD, S. A Interpretação dos sonhos (1900). Rio de Janeiro: Imago Ed., 2001. Ebook 